\title{
Hybrid Decision Models in Non-Proportional Reinsurance
}

\author{
Maik Wagner \\ Department of Business Statistics, Friedrich-Schiller-University Jena, Germany \\ E-mail:maik.wagner@uni-jena.de \\ Received November 18, 2009; revised December 14, 2009; accepted December 17, 2009
}

\begin{abstract}
Over the past years, risk measurement and therewith risk measures became more and more important in economics. While in the past risk measures were already adopted at the deposit of credit and shareholders equity, the approach now generates two hybrid decision models and applies them to the reinsurance business. The two introduced models implement a convex combination of risk measures and with it provide the possibility of modelling risk attitudes. By doing that, for the two hybrid decision models on the one hand can be shown, which risk attitude leads to the acceptance of a reinsurance contract and on the other hand, a deductible of which height an insurer is willing to undertake. Hence the possibility exists to identify the risk attitude of an insurer. In return, due to the knowledge of risk attitudes, under similar conditions the possibility arises to establish recommendations about the extent of the deductible at reinsurance contracts.
\end{abstract}

Keywords: Insurance; Optimization; Risk; Decision Analysis

\section{Introduction}

The application of risk measures gains more and more importance. These measures can be applied on the one hand in the determination of the deposit of equity capital and on the other hand in the modelling of decision models considering the risk attitude. First of all, in Section 2 a short insight into the topic reinsurance should be given, in order to introduce subsequently the profit function of an insurer for a non-proportional reinsurance contract. In Section 3 two complementary decision principles will be introduced. These use a hybrid preference functional for the determination of the deductible. With the help of this the optimal deductible of an insurer can be determined depending on the insurers risk attitude (see Section 4). The interpretation of the results follows in Section 5 and will be completed by a prospect in Section 6. Hence the aim of the article is to show possibilities of integrating risk attitudes into the determination of deductibles.

\section{Non-Proportional Reinsurance}

An insurer uses a reinsurance [1-3] for risk limitation and risk diversification of its compulsory treaty indemnity with its private customer. Thereby the aim of a reinsurance is to replace a part of the assumed ambiguous costs of the losses by fixed costs. These fixed costs represent the recompense of the reinsurance, the so-called reinsurance premium. Hence the reduction of the risk charge plays a central role for the insurer.

In this process reinsurance has two fundamental tasks: First, to restrain the annual variation of the loss burden of the insurer and second, to ensure the solvency of the insurance company in the extreme event of loss. Consequently the violation of the solvency [4] is the highest risk, which the insurer wants to avoid.

Reinsurance contracts can be distinguished in the reinsurance form and hence in the limitation of the obligation or voluntariness of the acceptance of risks, but also in their type. The distribution of risk is crucial for this differentiation between the insurer and the reinsurer. The risk is divided between the parties either in a proportional or non-proportional way $[5,6]$. In the following the focus is only on the non-proportional reinsurance.

The non-proportional reinsurance is characterized by a liability of the reinsurer which is only influenced by the amount of loss. This implies in connection of the arrangement of the contract, that the reinsurer only contributes to the loss in case the determined limit of loss is exceeded. This limit of loss is called deductible. The loss burden undertaken by the reinsurer is called reinsurance loss. It is necessary that the reinsurance loss

$$
R L(d, X)=\left\{\begin{array}{lll}
0, & \text { for } & x<d \\
X-d, & \text { for } & d \leq X
\end{array}=X-\min (d, X),\right.
$$

whereas $\mathrm{d}$ is the deductible and $\mathrm{X}$ the loss that evolves 
from the private customer business. The loss describes a random variable with a distribution function and the corresponding density $\mathrm{f}$. This density is zero for negative values, due to the non-existence of negative losses.

In return for the acquired reinsurance protection the insurer pays the reinsurance premium $\mathrm{RP}(\mathrm{d})$. The basic structure of such a premium contains the expected reinsurance loss and an additional profit mark-on. The profit mark-on can refer to the expected reinsurance loss on the one hand and to the variance or to the standard deviation on the other hand [7]. In the following the premium is applied with a profit mark-on, which is linked to the expected reinsurance loss.

\section{Definition 1}

$\mathrm{E}(\mathrm{RL}(\mathrm{d}, \mathrm{X}))$ is the expected reinsurance loss and $\gamma$ the profit mark-on of the reinsurer with $\gamma \geq 0$. Then $\mathrm{RP}(\mathrm{d}):=(1+\gamma) \mathrm{E}(\mathrm{RL}(\mathrm{d}, \mathrm{X}))$ is called reinsurance premium.

Additionally to the incomes and costs from the reinsurance business the reinsurer possesses the insurance premium $\mathrm{Pr}$ from the private customer business minus the loss X. Additionally the insurer has the costs of operation B. Consequently the profit function of an insurer has the following form

$$
\begin{aligned}
\mathrm{G}(\mathrm{d}, \mathrm{X}) & =\operatorname{Pr}-\mathrm{B}-\mathrm{X}-\mathrm{RP}(\mathrm{d})+\mathrm{X}-\min (\mathrm{d}, \mathrm{X}) \\
& =\operatorname{Pr}-\mathrm{B}-\mathrm{RP}(\mathrm{d})-\min (\mathrm{d}, \mathrm{X}) .
\end{aligned}
$$

an insurer has the choice between different decision principles. For each decision principle a preference functional, modelling its behaviour, exists. In this process the aim of an insurer is to maximize its profit function in reference to the deductible.

\section{Decision Principles}

A situation is identified as decision under risk [8,9] in case the possible entry scenarios as well as their entry probabilities are known. Consequently this case applies to an insurer, as the cedent knows the loss distribution from historical data and hence the insurer can estimate the possible loss as well as its probability.

In the following, two hybrid models are introduced and applied to the reinsurance problem. Both decision models represent a weighting between expected value and conditional expected value. The first preference functional uses the Conditional Value at Risk (the lower conditional expected value) and the second preference functional the upper conditional expected value of the target function.

The preference functionals have the following form

$$
\begin{aligned}
& \Phi_{\alpha, \lambda}(\mathrm{G}(\mathrm{d}, \mathrm{X}))=\frac{1-\lambda}{1-\alpha} \mathrm{E}(\mathrm{G}(\mathrm{d}, \mathrm{X})) \\
& +\frac{\lambda-\alpha}{1-\alpha} \mathrm{E}\left(\mathrm{G}(\mathrm{d}, \mathrm{X}) \mid \mathrm{G}(\mathrm{d}, \mathrm{X}) \leq \mathrm{g}_{\alpha}(\mathrm{d})\right)
\end{aligned}
$$

and

$$
\begin{aligned}
& \Phi_{\beta, \delta}(\mathrm{G}(\mathrm{d}, \mathrm{X}))=\frac{1-\delta}{1-\beta} \mathrm{E}(\mathrm{G}(\mathrm{d}, \mathrm{X})) \\
& +\frac{\delta-\beta}{1-\beta} \mathrm{E}\left(\mathrm{G}(\mathrm{d}, \mathrm{X}) \mid \mathrm{G}(\mathrm{d}, \mathrm{X}) \geq \mathrm{g}_{1-\beta}(\mathrm{d})\right),
\end{aligned}
$$

whereas $\alpha$ and $\lambda$ are the risk parameters of the first preference functional and $\beta$ and $\delta$ are the risk parameters of the second preference functional with $\alpha, \beta \in[0,1[$ and $\lambda, \delta \in[0,1]$. It is necessary that $\frac{1-\lambda}{1-\alpha}+\frac{\lambda-\alpha}{1-\alpha}=1$ and $\frac{1-\delta}{1-\beta}+\frac{\delta-\beta}{1-\beta}=1$. Furthermore $\mathrm{g}_{\alpha}(\mathrm{d})$ is the $\alpha$-quantile of the profit in the first and $\mathrm{g}_{1-\beta}(\mathrm{d})$ is the $(1-\beta)$ - quantile of the profit in the second functional. Both preference functionals can be applied amongst others in the Newsvendor problem $[10,11]$ with risk preferences $[12,13]$.

In the Newsvendor model a trader wants to sell a product at the price $\mathrm{p}$. However the product can only be sold within one time period. The trader buys the product at price $c$ and in case of not selling can return it at the price of $z$. The analogy between the News-vendor and the reinsurance model is represented in Poser, Wagner [14].

Both preference functionals represent risk neutrality in case of equality of their risk parameters. In this case both functionals are equal the expected profit. In case $\alpha<\lambda$ the lower expected value has a positive influence on the preference functional and represents risk aversion. Analogical in the second functional the upper expected value has a positive influence for $\beta<\delta$ and conse- quently reflects risk taking. In cases $\alpha>\lambda$ and $\beta>\delta$ the lower and upper expected value is integrated nega- tively and represents risk taking for the first decision functional and risk aversion for the second one. It should be present that the complementary preference functionals have the same results.

The two following questions shall be clarified for the two introduced preference functionals:

1) At which risk attitude the insurer decides in favour of the reinsurance?

2) If the insurer decides in favour of the reinsurance, which level of the deductible is preferred?

\section{Determination of the Deductible}

In this section the deductible is determined with the help of two preference functionals depending on the risk attitude of a decision maker. The profit function is dependent on the loss while the lower and upper expected value comprise the profit quantile.

From Chart 1 can be noticed, that the $\alpha \cdot 100 \%$ low- 


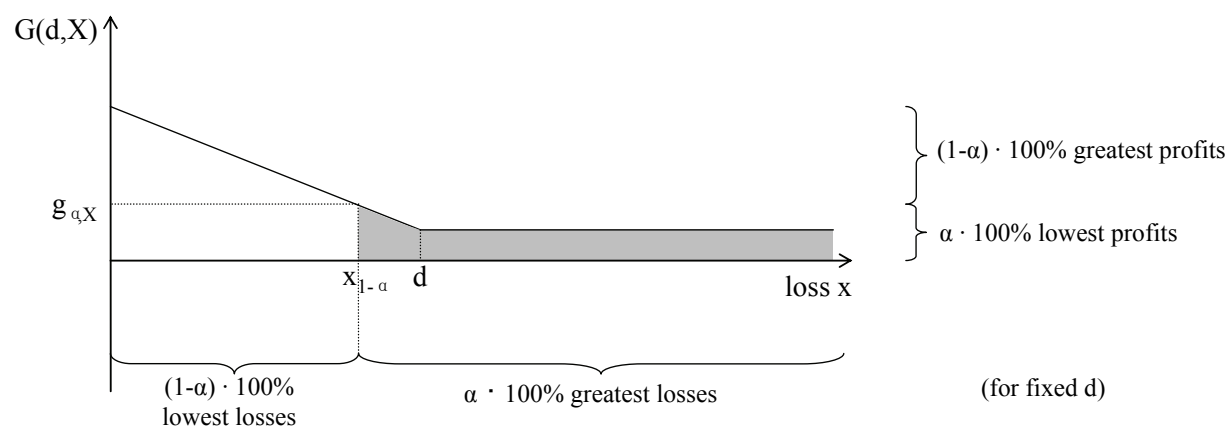

Chart 1. Profit function of the insurer with $\alpha$-profit quantile.
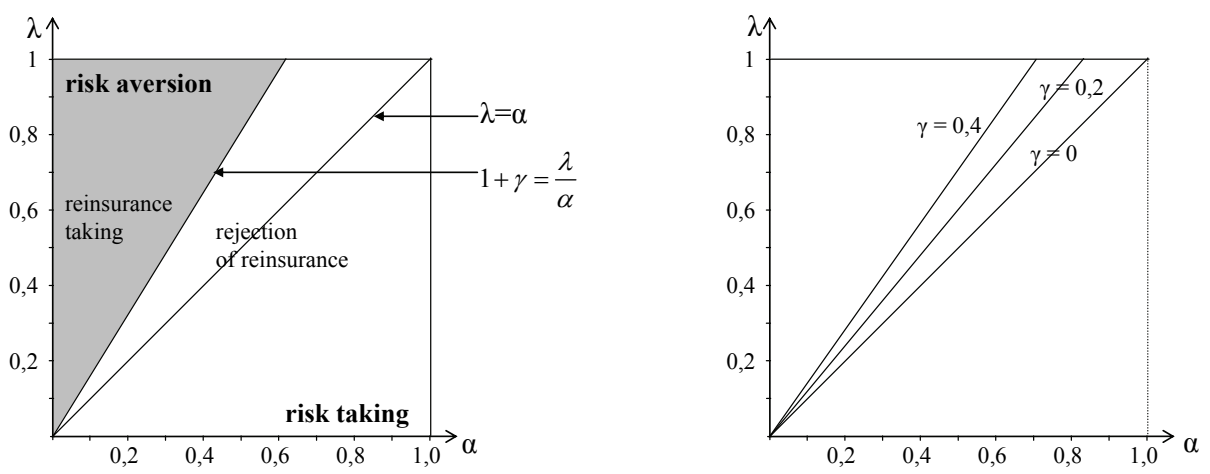

Chart 2. Risk preference space for the preference functional $\Phi_{\alpha, \lambda}(\mathrm{G}(\mathrm{d}, \mathrm{X}))$.

est profits are realized with the $\alpha \cdot 100 \%$ greatest losses. Consequently $(1-\alpha) \cdot 100 \%$ of the losses are located below the loss quantile. Consequently it is the $(1-\alpha)$-loss quantile.

Hence the following equation applies

$$
\mathrm{E}\left(\mathrm{G}(\mathrm{d}, \mathrm{X}) \mid \mathrm{G}(\mathrm{d}, \mathrm{X}) \leq \mathrm{g}_{\alpha}(\mathrm{d})\right)=\mathrm{E}\left(\mathrm{G}(\mathrm{d}, \mathrm{X}) \mid \mathrm{X} \geq \mathrm{x}_{1-\alpha}\right),
$$

whereas $\mathrm{x}_{1-\alpha}$ indicates the loss quantile. Analogical the $\beta \cdot 100 \%$ greatest profits ${ }^{1}$ appear at the $\beta \cdot 100 \%$ lowest losses. $\beta \cdot 100 \%$ of the losses are located below the $\beta$-loss quantile. Hence the following applies

$$
\mathrm{E}\left(\mathrm{G}(\mathrm{d}, \mathrm{X}) \mid \mathrm{G}(\mathrm{d}, \mathrm{X}) \geq \mathrm{g}_{1-\beta}(\mathrm{d})\right)=\mathrm{E}\left(\mathrm{G}(\mathrm{d}, \mathrm{X}) \mid \mathrm{X} \leq \mathrm{x}_{\beta}\right),
$$

whereas $x_{\beta}$ characterizes the $\beta$-loss quantile. Hence it is possible to maximize the two preference functionals. The two following theorems verbalize this.

\section{Theorem 1}

Let $G(d, X)=\operatorname{Pr}-B-R V P(d)-\min (d, X) \quad$ be the profit function of an insurer and

$$
\begin{aligned}
& \Phi_{\alpha, \lambda}(\mathrm{G}(\mathrm{d}, \mathrm{X}))=\frac{1-\lambda}{1-\alpha} \mathrm{E}(\mathrm{G}(\mathrm{d}, \mathrm{X})) \\
& +\frac{\lambda-\alpha}{1-\alpha} \mathrm{E}\left(\mathrm{G}(\mathrm{d}, \mathrm{X}) \mid \mathrm{X} \geq \mathrm{x}_{1-\alpha}\right)
\end{aligned}
$$

\footnotetext{
${ }^{1}$ These are the profits lying above the $(1-\beta)$-profit quantile.

${ }^{2}$ The proof of theorem Theorem 1 can be found in the appendix.
}

its objective function. Then the maximizing problem $\max _{\mathrm{d}} \Phi_{\alpha, \lambda}(\mathrm{G}(\mathrm{d}, \mathrm{X}))$ has the following implicit solution

$$
\mathrm{F}_{\mathrm{X}}\left(\mathrm{d}^{*}(\alpha, \lambda)\right)= \begin{cases}1, & \text { for } 1+\gamma>\frac{\lambda}{\alpha} \\ \frac{(1-\alpha) \gamma}{(1-\alpha)(1+\gamma)-(1-\lambda)}, & \text { for } 1+\gamma<\frac{\lambda}{\alpha}\end{cases}
$$

with $\alpha \in] 0,1\left[, \lambda \in[0,1]\right.$ and $\gamma \geq 0 .^{2}$

\section{Theorem 2}

Let $G(d, X)=\operatorname{Pr}-B-R V P(d)-\min (d, X)$ be the profit function of an insurer and

$$
\begin{aligned}
& \Phi_{\beta, \delta}(\mathrm{G}(\mathrm{d}, \mathrm{X}))=\frac{1-\delta}{1-\beta} \mathrm{E}(\mathrm{G}(\mathrm{d}, \mathrm{X})) \\
& +\frac{\delta-\beta}{1-\beta} \mathrm{E}\left(\mathrm{G}(\mathrm{d}, \mathrm{X}) \mid \mathrm{X} \leq \mathrm{x}_{\beta}\right)
\end{aligned}
$$

its objective function. Then this maximizing problem $\max _{d} \Phi_{\beta, \delta}(G(d, X))$ has the following implicit solution

$$
\mathrm{F}_{\mathrm{X}}\left(\mathrm{d}^{*}(\alpha, \lambda)\right)= \begin{cases}1, & \text { for } 1+\gamma>\frac{1-\delta}{1-\beta} \\ \frac{\beta \gamma}{\beta(1+\gamma)-\delta}, & \text { for } 1+\gamma<\frac{1-\delta}{1-\beta}\end{cases}
$$

with $\beta \in] 0,1[, \delta \in[0,1]$ and $\gamma \geq 0[16]$. 

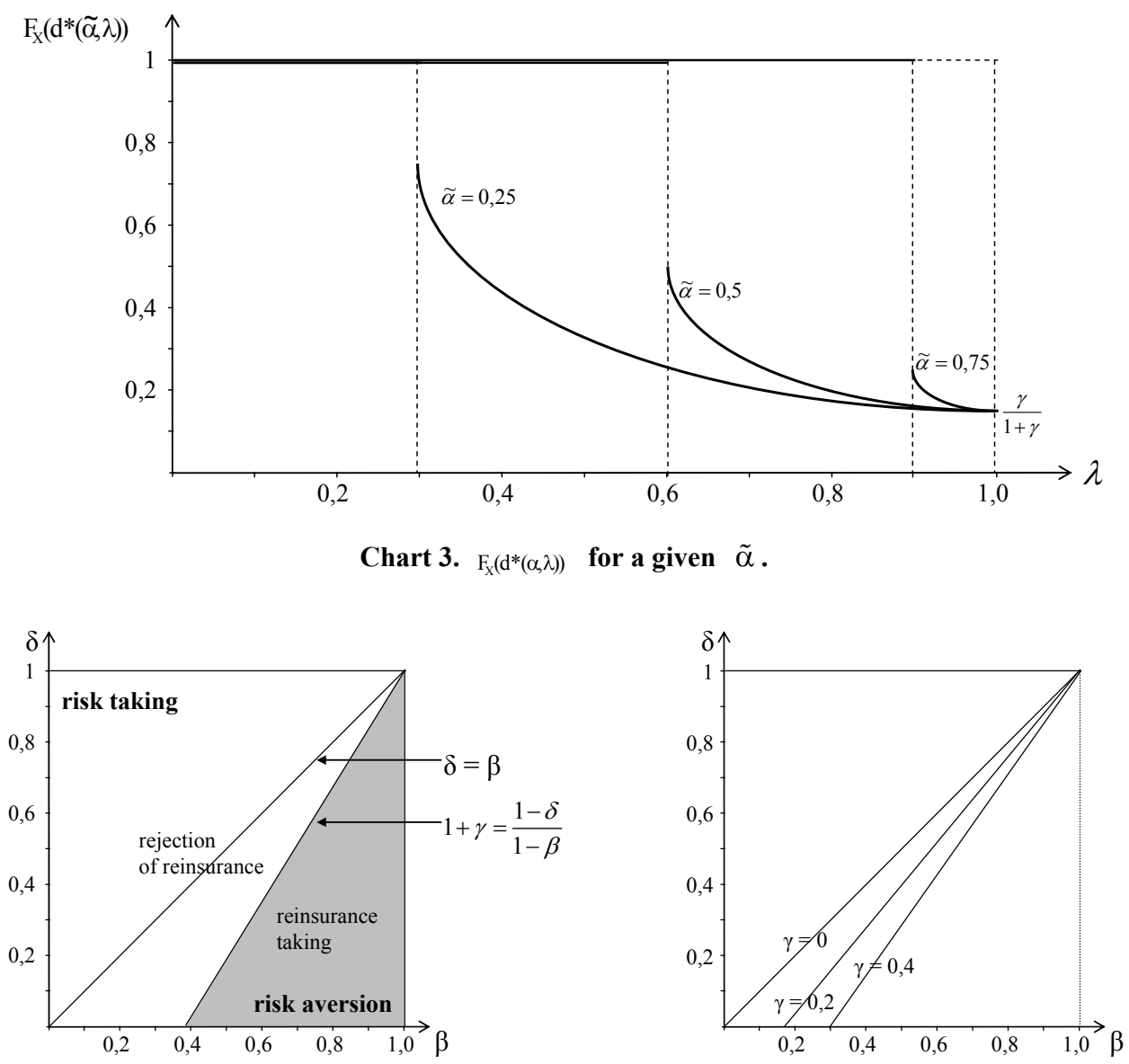

Chart 4. Risk preference space for $\Phi_{\beta, \delta}(G(d, X))$ •

\section{Interpretation}

At first the risk preference space for the preference functional $\Phi_{\alpha, \lambda}(G(d, X))$ is examined. This one is illustrated by the left figure of the Chart 2 . The space is splitted into two halves by the angle bisector. The surface above the angle bisector $(\alpha<\lambda)$ contains all $\alpha-\lambda-$ combinations for risk aversion and below $(\alpha>\lambda)$ all combinations for risk taking. The angle bisector $(\alpha=\lambda)$ itself is the combination for risk neutrality.

Furthermore within this figure appears the border between the optimal solutions $1+\gamma=\frac{\lambda}{\alpha}$. The value of the distribution at the optimal deductible below that border thereby is $\mathrm{F}_{\mathrm{X}}\left(\mathrm{d}^{*}(\alpha, \lambda)\right)=1$ and above $\mathrm{F}_{\mathrm{X}}(\mathrm{d} *(\alpha, \lambda))=\frac{(1-\alpha) \gamma}{(1-\alpha)(1+\gamma)-(1-\lambda)}$.

The conclusion can be drawn, that the insurer with $F_{X}\left(d^{*}(\alpha, \lambda)\right)=1$ chooses a deductible to the extent of the greatest losses. This implies, that the insurer wants to bear every occurred loss himself. In this case the cedent rejects the reinsurance. In the case $1+\gamma<\frac{\lambda}{\alpha}$ the distribution of the optimal deductible fulfils

$$
\mathrm{F}_{\mathrm{X}}\left(\mathrm{d}^{*}(\alpha, \lambda)\right)=\frac{(1-\alpha) \gamma}{(1-\alpha)(1+\gamma)-(1-\lambda)} \in[0,1-\alpha] .
$$

That implies, that the insurer intends to take the reinsurance. At the border $1+\gamma=\frac{\lambda}{\alpha}$ the insurer is indifferent between the optimal solutions.

The right figure of Chart 2 illustrates the changing of the border between contract taking and rejection depending on the profit mark-on of the reinsurer. The border moves in an area of higher risk aversion for a higher profit mark-on $\gamma$. So the insurer has to surmount this mark-on before he chooses the contract. In case, that the profit mark-on gamma is zero the risk neutrality line is the border between contract taking and rejection.

A further question is: If the insurer decides in favour of the reinsurance, which level of deductible is preferred? It can be adhered, that in case of choosing the reinsurance the value of the distribution at the optimal 


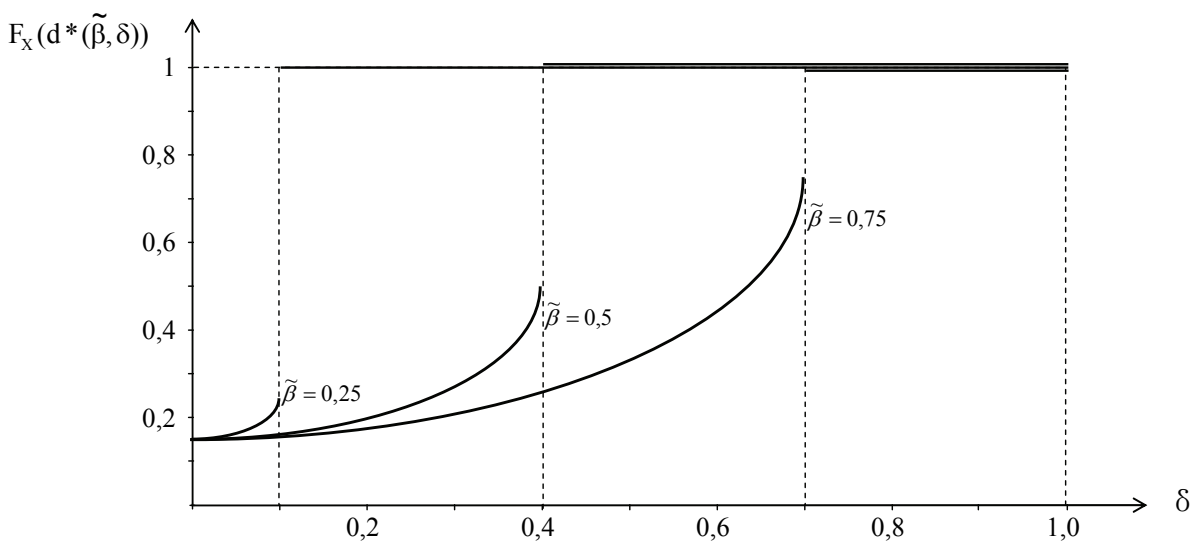

Chart 5. $F_{x}\left(d^{*}(\beta, \delta)\right)$ for a given $\tilde{\beta}$.

deductible decreases with the increase of risk aversion $(\lambda \rightarrow 1)$. That implies, that the cedent wants to release more risk to the cessionary. Chart 3 illustrates this for a given $\alpha$.

At the point of the highest risk aversion $(\lambda=1)$ the value of the distribution at the optimal deductible is $\frac{\gamma}{1+\gamma}$ and so independent of the risk parameter $\alpha$. Within the chart a profit mark-on of $20 \%$ is assumed.

Now the results of the preference functional $\Phi_{\beta, \delta}(\mathrm{G}(\mathrm{d}, \mathrm{X}))$ are observed. The left figure of Chart 4 shows the risk preference of the preference functional. The space is divided into two halves by the angle bisector as well. This time the space above the angle bisector $(\beta<\delta)$ contains all $\beta$ - $\delta$-combinations for risk taking and below all combinations for risk aversion. The angle bisector itself describes the combination for risk neutrality.

Likewise the border between the optimal solutions $\left(1+\gamma=\frac{1-\delta}{1-\beta}\right)$ is illustrated in this figure. The value of the distribution at the optimal deductible above this border is $\mathrm{F}_{\mathrm{X}}\left(\mathrm{d}^{*}(\beta, \delta)\right)=1$ and below

$$
\mathrm{F}_{\mathrm{X}}\left(\mathrm{d}^{*}(\beta, \delta)\right)=\frac{\beta \gamma}{\beta(1+\gamma)-\delta} .
$$

It can be concluded, that an insurer with $\mathrm{F}_{\mathrm{X}}\left(\mathrm{d}^{*}(\beta, \delta)\right)=1$ chooses the deductible in the amount of the greatest possible loss and consequently rejects the reinsurance.

In the case $1+\gamma=\frac{1-\delta}{1-\beta}$ the value of the distribution at the optimal deductible fulfils

$$
\mathrm{F}_{\mathrm{X}}(\mathrm{d} *(\beta, \delta))=\frac{\beta \gamma}{\beta(1+\gamma)-\delta} \in[0, \beta[.
$$

Hence the cedent decides in favour of the reinsurance. The border between accepting and rejecting the reinsurance depending on the profit mark-on of the reinsurer, is illustrated by the right figure of Chart 4 .

It likewise can be recognized, that the purchase decision of the reinsurance moves in an area of higher risk aversion with increasing profit mark-on of the reinsurer. Consequently it is necessary that the higher the profit mark-on of the reinsurer is, the greater the risk aversion of the decision maker has to be, so that he purchases the reinsurance.

Concluding this, the following question remains: Which deductible, depending on the risk attitude with the $\beta-\delta$-preference functional, does the insurer choose in case of accepting the reinsurance? In this situation the value of the distribution at the optimal deductible decreases with an increase of risk aversion $(\delta \rightarrow 0)$. That means, that the insurer wants to release more risk to the reinsurer. This is illustrated by Chart 5 for a given $\beta$.

Concerning both decision principles it can be concluded, that risk taking as well as risk neutral insurers reject the reinsurance. For risk aversion in contrast, two cases can be distinguished: On the one hand the case of lower risk aversion $\left(1+\gamma>\frac{\lambda}{\alpha}\right.$ rather $\left.1+\gamma>\frac{1-\delta}{1-\beta}\right)$, where the reinsurance is rejected as well and on the other hand the case of higher risk aversion $\left(1+\gamma<\frac{\lambda}{\alpha}\right.$ rather $\left.1+\gamma<\frac{1-\delta}{1-\beta}\right)$, where the insurer decides in favour of the reinsurance. That implies that only an insurer having enough risk aversion decides to take the reinsurance. In case that the reinsurance is accepted, the deductible decreases with the increase of risk aversion. It can be stated, that the higher the risk aversion is, the more risk is transferred to the reinsurer by the cedent. 
The interpretations of results are identical for both preference functionals. For this reason it is irrelevant, whether using the preference functional with the lower or with the upper expected value. It is possible to find for each $\alpha-\lambda$-combination of the first preference funktional a $\beta-\delta$-combination of the second preference funktional.

The analogy is $\alpha=1-\beta$ and $\lambda=1-\delta$.

\section{Prospect}

With the solutions of the optimal deductible it is possible to detect the risk preference of the insurer in case of knowing the loss distribution and the coverage limit. Furthermore the optimal deductible for a different assumed loss distribution can be calculated when knowing the risk preference of the insurer.

The introduced models only consider the maximization of the profit function in reference to the deductible. One possible prospect is the application of the hybrid decision model for the maximization of the profit function in reference to the cover or continuative the maximazation of a two dimensional model with deductible and cover.

Furthermore an investigation of the models could be made with the use of a fair premium and also the consistence to decision theories could be established.

\section{References}

[1] K. Gerathewohl, "Reinsurance principles and practice," Vol. 1, Verlag Versicherungswirtschaft, Karlsruhe, 1980.

[2] E. Wollan, "Handbook of reinsurance law," Aspen Publishers, New York, 2002.

[3] S. C. Bennett, "Dictionary of insurance, pearson education," Zug, 2004.
[4] E. Helland, C. R. Nysæter, "Solvency II: An Illustration, " Forfatterne, Bergen, 2006.

[5] A. Schwepcke, D. Arndt, "Reinsurance: Principles and state of the art," Verlag Versicherungswirtschaft, Karlsruhe, 2004.

[6] R. Phifer, "Reinsurance fundamentals: Treaty and facultative," John Wiley, New York, 1996.

[7] M. Kaluszka, "Optimal reinsurance under mean-variance premium principles," Insurance: Mathematics and Economics, Vol. 42, 2008.

[8] P. J. Montana, B. H. Charnov, "Management, Barron's educational series," New York, 2000.

[9] V. Torra, Y. Narukawa, "Modeling Decisions for Artificial Intelligence," Springer, 2009.

[10] G. Cachon and C. Terwiesch, "Matching supply with demand," Mc Graw-Hill, New York, 2006.

[11] S. Chopra and P. Meindl, "Supply chain management," 2. Edition, Prentice Hall, New Jersey, 2004.

[12] W. Jammernegg and P. Kischka, "A decision rule based on the conditional value at risk," Jenaer Schriften zur Wirtschaftswissenschaft, Vol. 9, 2005.

[13] W. Jammernegg and P. Kischka, "Risk-averse and risk-taking newsvendors: A conditional expected value approach," Review of Managerial Science, Vol. 1, 2007.

[14] K. Poser, M. Wagner, "Das Newsvendor Modell mit nicht-linearer Kostenfunktion und seine Anwendung bei nicht-proportionalen Rückversicherungsverträgen," Jena Research Papers in Business and Economics, Vol. 15, 2007.

[15] P. Embrechts, R. Frey, and A. J. McNeil, "Quantitative risk management: Concepts," Techniques and Tools, Princeton University Press, Oxford, 2005.

[16] M. Wagner, "Bestimmung von Deckungsgrenzen bei nicht-proportionalen Rueckversicherungsvertraegen," German Journal of Risk and Insurance, Vol. 3, 2008. 


\section{Appendix}

Proof of Theorem 1:

The following applies

$$
\begin{aligned}
\Phi_{\alpha, \lambda}(\mathrm{G}(\mathrm{d}, \mathrm{X})) & =\frac{1-\lambda}{1-\alpha} \mathrm{E}(\mathrm{G}(\mathrm{d}, \mathrm{X})) \\
& +\frac{\lambda-\alpha}{1-\alpha} \mathrm{E}\left(\mathrm{G}(\mathrm{d}, \mathrm{X}) \mid \mathrm{X} \geq \mathrm{x}_{1-\alpha}\right)
\end{aligned}
$$

The first derivation of the preference functional is generated and the following can be received

$$
\begin{aligned}
\mathrm{D}_{\mathrm{d}}\left(\Phi_{\alpha, \lambda}(\mathrm{G}(\mathrm{d}, \mathrm{X}))\right) & =\frac{1-\lambda}{1-\alpha} \mathrm{D}_{\mathrm{d}}(\mathrm{E}(\mathrm{G}(\mathrm{d}, \mathrm{X}))) \\
& +\frac{\lambda-\alpha}{1-\alpha} \mathrm{D}_{\mathrm{d}}\left(\mathrm{E}\left(\mathrm{G}(\mathrm{d}, \mathrm{X}) \mid \mathrm{X} \geq \mathrm{x}_{1-\alpha}\right)\right) .
\end{aligned}
$$

At first the first differential of the expected profit and also of the conditional expected value has to be determined. For the profit function of the insurer can be assumed $\mathrm{G}(\mathrm{d}, \mathrm{X})=\mathrm{Pr}-\mathrm{B}-\mathrm{X}-\mathrm{RP}(\mathrm{d})+\mathrm{RL}(\mathrm{d}, \mathrm{X})$. For the expected profit can be obtained

$$
\begin{aligned}
& E(G(d, X))=E\left(\operatorname{Pr}-B-X-R P(d)+\left\{\begin{array}{ll}
0, & \text { for } \quad X<d \\
X-d, & \text { for } \quad d \leq X
\end{array}\right)\right. \\
& =\operatorname{Pr}-\mathrm{B}-\mathrm{E}(\mathrm{X})-\mathrm{RP}(\mathrm{d})+\int_{0}^{\mathrm{d}} 0 \mathrm{dF}_{\mathrm{X}}(\mathrm{x})+\int_{\mathrm{d}}^{\infty}(\mathrm{x}-\mathrm{d}) \mathrm{dF}_{\mathrm{X}}(\mathrm{x}) \\
& =\operatorname{Pr}-\mathrm{B}-\mathrm{E}(\mathrm{X})-\mathrm{RP}(\mathrm{d})+\int_{\mathrm{d}}^{\infty}(\mathrm{x}-\mathrm{d}) \mathrm{dF}_{\mathrm{X}}(\mathrm{x})^{3} \\
& =\operatorname{Pr}-\mathrm{B}-\mathrm{E}(\mathrm{X})-\mathrm{RP}(\mathrm{d})+\int_{\mathrm{d}}^{\infty} \mathrm{xdF} \mathrm{F}_{\mathrm{X}}(\mathrm{x})-\mathrm{d}\left[1-\mathrm{F}_{\mathrm{X}}(\mathrm{d})\right] .
\end{aligned}
$$

By the use of differentiation and the main theorem of the infinitesimal calculus for the expected profit follows

$$
\begin{aligned}
D_{d}(E(G(d, X))) & =-R P_{d}(d)-d \cdot f_{X}(d)-\left(1-F_{X}(d)\right)+d \cdot f_{X}(d) \\
& =-R P_{d}(d)-1+F_{X}(d)
\end{aligned}
$$

In the case $F_{X}(d) \geq 1-\alpha$ is for the conditional expected value essential, that

$$
\begin{aligned}
& \mathrm{E}\left(\mathrm{G}(\mathrm{d}, \mathrm{x}) \mid \mathrm{X} \geq \mathrm{x}_{1-\alpha}\right) \\
& \quad=\frac{1}{\alpha}[\operatorname{Pr}-\mathrm{B}-\mathrm{RP}(\mathrm{d})][1-(1-\alpha)]-\frac{1}{\alpha} \mathrm{d}\left[1-\mathrm{F}_{\mathrm{X}}(\mathrm{d})\right]
\end{aligned}
$$

\footnotetext{
${ }^{3}$ It is necessary that

$\int_{d}^{\infty}(x-d) d F_{X}(x)=\int_{d}^{\infty} x d F_{X}(x)-\int_{d}^{\infty} d d F_{x}(x)=\int_{d}^{\infty} x d F_{x}(x)-d \int_{d}^{\infty} d F_{x}(x)=$

$\int_{0}^{\infty} x d F_{x}(x)-d\left[1-F_{x}(d)\right]$

${ }^{4}$ It is necessary that $\frac{1-\lambda}{1-\alpha}+\frac{\lambda-\alpha}{1-\alpha} \frac{1}{\alpha}=\frac{\alpha(1-\lambda)+\lambda-\alpha}{\alpha(1-\alpha)}=$

$\frac{\alpha-\alpha \lambda+\lambda-\alpha}{\alpha(1-\alpha)}=\frac{\lambda(1-\alpha)}{\alpha(1-\alpha)}=\frac{\lambda}{\alpha}$.

${ }^{5}$ It is necessary that $\mathrm{RP}_{\mathrm{d}}(\mathrm{d})=(1+\gamma)\left[-1+\mathrm{F}_{\mathrm{X}}(\mathrm{d})\right]$.
}

$$
\begin{aligned}
& -\frac{1}{\alpha} \int_{F_{x}^{-1}(1-\alpha)}^{\mathrm{d}} \mathrm{xdF}_{\mathrm{X}}(\mathrm{x}) \\
& =[\operatorname{Pr}-\mathrm{B}-\mathrm{RP}(\mathrm{d})]-\frac{1}{\alpha} \mathrm{d}\left[1-\mathrm{F}_{\mathrm{X}}(\mathrm{d})\right] \\
& -\frac{1}{\alpha} \int_{\mathrm{F}_{\mathrm{X}}^{-1}(1-\alpha)}^{\mathrm{d}} \mathrm{xdF}_{\mathrm{X}},
\end{aligned}
$$

whereas $\mathrm{F}^{-1}$ is the inverse function of the loss distribution. In general, the generalized lower inverse

$\mathrm{F}^{*}$ (a) of the distribution function $\mathrm{F}(\mathrm{x})$ is required.

This has the following definition $\mathrm{F}^{*}(\mathrm{a}):=$ $\sup (x \in \operatorname{IR} \mid F(x) \leq a)$, whereas $a \in[0,1]$. On the contrary, if one assumes a continuous and strictly increasing distribution function then the generalized lower inverse is equal to the inverse function $\mathrm{F}^{-1}$ of the loss distribution. In the following a continuous and strictly increasing distribution function should be assumed.

The first derivation of the conditional expected value is

$$
\begin{aligned}
D_{d} & \left(E\left(G(d, x) \mid X \geq x_{1-\alpha}\right)\right) \\
& =-R_{d}(d)-\frac{1}{\alpha}\left(1-F_{X}(d)\right)+\frac{1}{\alpha} d f_{X}(d)-\frac{1}{\alpha} d f_{X}(d) \\
& =-R_{d}(d)-\frac{1}{\alpha}\left(1-F_{X}(d)\right)
\end{aligned}
$$

and so it is essential for the first derivation of the preference functional, that

$$
\begin{aligned}
\mathrm{D}_{\mathrm{d}} & \left(\Phi_{\alpha, \lambda}(\mathrm{G}(\mathrm{d}, \mathrm{X}))\right) \\
& =\frac{1-\lambda}{1-\alpha}\left[-\mathrm{RP}_{\mathrm{d}}(\mathrm{d})-1+\mathrm{F}(\mathrm{d})\right. \\
& +\frac{\lambda-\alpha}{1-\alpha}\left[-\mathrm{RP}_{\mathrm{d}}(\mathrm{d})-\frac{1}{\alpha}\left(1-\mathrm{F}_{\mathrm{X}}(\mathrm{d})\right)\right] \\
& =-\mathrm{RP}_{\mathrm{d}}(\mathrm{d})+\left[\frac{1-\lambda}{1-\alpha}+\frac{\lambda-\alpha}{1-\alpha} \frac{1}{\alpha}\right]\left[-1+\mathrm{F}_{\mathrm{X}}(\mathrm{d})\right] \\
& =-\mathrm{RP}_{\mathrm{d}}(\mathrm{d})+\frac{\lambda}{\alpha}\left[-1+\mathrm{F}_{\mathrm{X}}(\mathrm{d})\right]{ }^{4} \\
& =-(1+\gamma)\left[-1+\mathrm{F}_{\mathrm{X}}(\mathrm{d})\right]+\frac{\lambda}{\alpha}\left[-1+\mathrm{F}_{\mathrm{X}}(\mathrm{d})\right] \\
& =\left[\frac{\lambda}{\alpha}-(1+\gamma)\right]\left[-1+\mathrm{F}_{\mathrm{X}}(\mathrm{d})\right] .
\end{aligned}
$$

Therefore the optimal solution $\mathrm{F}_{\mathrm{X}}\left(\mathrm{d}^{*}\right)=1$ can be obtained. For the second derivation of the preference functional follows

$$
\begin{aligned}
& \mathrm{D}_{\mathrm{dd}}\left(\Phi_{\alpha, \lambda}(\mathrm{G}(\mathrm{d}, \mathrm{X}))\right)=\left[\frac{\lambda}{\alpha}-(1+\gamma)\right] \mathrm{f}_{\mathrm{X}}(\mathrm{d}) . \\
& \text { It is necessary that }\left[-(1+\gamma)+\frac{\lambda}{\alpha}\right] \mathrm{f}_{\mathrm{X}}\left(\mathrm{d}^{*}\right)<0 \text { and }
\end{aligned}
$$


$1+\gamma>\frac{\lambda}{\alpha}$ because the loss density is not negative.

Hence $\mathrm{F}_{\mathrm{X}}\left(\mathrm{d}^{*}(\alpha, \lambda)\right)=1$ is the maximum in the case of $1+\gamma>\frac{\lambda}{\alpha}$.

In the case $F_{X}(d)<1-\alpha$ the conditional expected value is

$$
\begin{aligned}
& \mathrm{E}\left(\mathrm{G}(\mathrm{d}, \mathrm{X}) \mid \mathrm{X} \geq \mathrm{x}_{1-\alpha}\right) \\
& =\frac{1}{\alpha} \int_{\mathrm{F}_{\mathrm{x}}^{-1}(1-\alpha)}^{\infty}[\operatorname{Pr}-\mathrm{B}-\mathrm{RP}(\mathrm{d})-\mathrm{x}+\mathrm{x}-\mathrm{d}] \mathrm{dF}_{\mathrm{X}}(\mathrm{x}) \\
& -\frac{1}{\alpha}[\operatorname{Pr}-\mathrm{B}-\mathrm{RP}(\mathrm{d})-\mathrm{d}] \int_{\mathrm{F}_{\mathrm{X}}^{\prime}(1-\alpha)}^{\infty} \mathrm{dF}_{\mathrm{X}}(\mathrm{x}) \\
& =\frac{1}{\alpha}[\operatorname{Pr}-\mathrm{B}-\mathrm{RP}(\mathrm{d})-\mathrm{d}][1-(1-\alpha)] \\
& -\operatorname{Pr}-\mathrm{B}-\mathrm{RP}(\mathrm{d})-\mathrm{d},
\end{aligned}
$$

After differentiation it is necessary that $\mathrm{D}_{\mathrm{d}}\left(\mathrm{E}\left(\mathrm{G}(\mathrm{d}, \mathrm{X}) \mid \mathrm{X} \geq \mathrm{x}_{1-\alpha}\right)\right)=-\mathrm{RP}_{\mathrm{d}}(\mathrm{d})-1$.

Consequently for the first derivation of the preference functional can be obtained

$$
\begin{aligned}
& \mathrm{D}_{\mathrm{d}}\left(\Phi_{\alpha, \lambda}(\mathrm{G}(\mathrm{d}, \mathrm{X}))\right) \\
& =\frac{1-\lambda}{1-\alpha}\left[-\mathrm{RP}_{\mathrm{d}}(\mathrm{d})-1+\mathrm{F}_{\mathrm{X}}(\mathrm{d})\right]+\frac{\lambda-\alpha}{1-\alpha}\left[-\mathrm{RP}_{\mathrm{d}}(\mathrm{d})-1\right] \\
& =-\mathrm{RP}_{\mathrm{d}}(\mathrm{d})-1+\frac{1-\lambda}{1-\alpha} \mathrm{F}_{\mathrm{X}}(\mathrm{d}) \\
& =-(1+\gamma)\left[-1+\mathrm{F}_{\mathrm{X}}(\mathrm{d})-1+\frac{1-\lambda}{1-\alpha} \mathrm{F}_{\mathrm{X}}(\mathrm{d})^{6}\right. \\
& =\gamma+\left[-(1+\gamma)+\frac{1-\lambda}{1-\alpha}\right] \mathrm{F}_{\mathrm{X}}(\mathrm{d})
\end{aligned}
$$

Therefore the optimal solution is

$$
\mathrm{F}_{\mathrm{X}}\left(\mathrm{d}^{*}(\alpha, \lambda)\right)=\frac{(1-\alpha) \gamma}{(1-\alpha)(1+\gamma)-(1-\lambda)} \text {. }
$$

Now the determination of the second derivation for the identification of the type of optimum can be made. It is necessary that

$$
\mathrm{D}_{\mathrm{dd}}\left(\Phi_{\alpha, \lambda}(\mathrm{G}(\mathrm{d}, \mathrm{X}))\right)=\left[-1\left(1+\gamma+\frac{1-\lambda}{1-\alpha}\right] \mathrm{f}_{\mathrm{X}}(\mathrm{d}) .\right.
$$

As the loss density can not receive negative values, the second derivation of the preference functional is negative in case that $1+\gamma>\frac{1-\lambda}{1-\alpha}$. The following question arises: When does the optimum exist? At first $\mathrm{F}_{\mathrm{X}}\left(\mathrm{d}^{*}(\alpha, \lambda)\right) \geq 0$ is observed. This equation can be assumed, when the denominator of the solution is not negative. It is necessary, that

$$
(1-\alpha)(1+\gamma)-(1-\lambda) \geq 0 \Rightarrow 1+\gamma \geq \frac{1-\lambda}{1-\alpha} .
$$

Therefore $\mathrm{F}_{\mathrm{X}}(\mathrm{d} *(\alpha, \lambda))$ is a maximum, for $\mathrm{F}_{\mathrm{X}}\left(\mathrm{d}^{*}(\alpha, \lambda)\right) \geq 0$. The second step $\mathrm{F}_{\mathrm{X}}\left(\mathrm{d}^{*}(\alpha, \lambda)\right)<1-\alpha$ is observed. It is necessary, that

$$
\frac{\gamma(1-\alpha)}{(1-\alpha)(1+\gamma)-(1-\lambda)}<1-\alpha
$$

and this is equivalent to $1+\gamma<\frac{\lambda}{\alpha}$, because

$$
\begin{aligned}
& \frac{\gamma(1-\alpha)}{(1-\alpha)(1+\gamma)-(1-\lambda)}<1-\alpha & \Rightarrow \gamma<(1-\alpha)(1+\gamma)-(1-\lambda) \\
\Rightarrow \quad(1-\alpha)(1+\gamma)-(1+\gamma)+\lambda>0 & \Rightarrow & (1-\alpha-1)(1+\gamma)+\lambda>0 \\
\Rightarrow-\alpha(1+\gamma)+\lambda>0 & \Rightarrow & 1+\gamma>\frac{\lambda}{\alpha}
\end{aligned}
$$

The result is, that the maximum exists, when the other maximum $\mathrm{F}_{\mathrm{X}}\left(\mathrm{d}^{*}(\alpha, \lambda)\right)=1$ does not exist.

${ }^{6}$ It is necessary that $\operatorname{RVP}_{d}(d)=(1+\gamma)\left[-1+\mathrm{F}_{\mathrm{X}}(\mathrm{d})\right]$. 